\title{
Desplazamiento, ritualidad y configuración espacial. El Señor de los Milagros en Barcelona
}

Wilson Muñoz-Henríquez. Universidad de Tarapacá, Arica, Chile.

María-Esther Fernández-Mostaza. Universitat Autònoma de Barcelona, Barcelona, España.

RESUMEN | La procesión del Señor de los Milagros es una multitudinaria manifestación religiosa originaria de Perú, que recorre una infinidad de ciudades del mundo durante el mes de octubre. El artículo analiza la relación entre esta manifestación ritual en Barcelona y la reconfiguración espacial que involucra, centrándose en la práctica de la danza. Como estrategia metodológica principal utilizamos una etnografía focalizada en la procesión, la cual se desarrolló en Barcelona (España) durante los años 2016, 2017 y 2018. De manera complementaria se realizaron entrevistas en profundidad a informantes clave, focus groups y búsqueda de información documental e histórica. A lo largo del artículo evidenciamos que la procesión del Señor de los Milagros, y la reconfiguración espacial que conlleva, son fenómenos coproducidos ritualmente. La procesión operaría, consecuentemente, como un micropaisaje ritual móvil junto a la manifestación ritualizada de diferencias y tensiones culturales.

PALABRAS Clave | cultura urbana, espacio público, migración.

ABSTRACT | The procession of the Lord of Miracles is a massive religious manifestation originally from Peru, that has taken place during October in several cities around the world. The aim of this article is to analyze the relationship between this ritual manifestation (for the case of Barcelona) and the spatial reconfiguration that it involves, focusing specifically on the practice of dance. As a main methodological strategy, we use ethnography focused on the procession that took place in Barcelona (Spain) for the years of 2016, 2017 and 2018. Additionally, we conducted in-depth interviews with key informants, focus groups and we searched for documentary and historical information. Throughout the article, we show that the procession of the Lord of Miracles and the spatial reconfiguration that it entails are co-produced ritual phenomena. The procession would operate, consequently, as a mobile micro-landscape ritual, along with the ritualized manifestation of cultural differences and tensions.

KEYwORDs | urban culture, public space, migration.

Recibido el 4 de julio de 2019, aprobado el 10 de septiembre de 2019.

E-mails: W. Muńoz-Hneríquez, wilsonsocio@gmail.com | M.E. Fernández-Mostaza, mariaesther.fernandez@uab.cat 


\section{Introducción}

La procesión del Señor de los Milagros es una manifestación religiosa de carácter multitudinario que, cada mes de octubre, recorre una infinidad de ciudades de todo el mundo. En Barcelona (España), centenares de migrantes, mayoritariamente peruanos (aunque también de otros países latinoamericanos), se reúnen para participar en una espectacular procesión en torno al Cristo Moreno, como también le suelen llamar. Sin temor a equivocarnos, afirmamos que actualmente es la celebración más importante desarrollada en el espacio urbano de los peruanos y sus descendientes residentes en Barcelona.

A partir de nuestra reciente experiencia etnográfica en la ciudad de Barcelona (2016, 2017 y 2018) y de nuestro análisis de información histórica y documental preliminar, hemos podido advertir dos fenómenos significativos. Por un lado, que la procesión del Señor de los Milagros es una manifestación ritual compleja, donde la recreación de elementos culturales, étnicos, religiosos y políticos ha estado históricamente vinculada con su manifestación en el espacio público, desde sus orígenes en Lima hasta sus manifestaciones más recientes en Barcelona. En este contexto, una de las prácticas más distintivas y potentes de este fenómeno ha sido la danza (o danzas) que se ejecutan en su seno, las cuales entenderemos como una manifestación ritual, es decir: una práctica social particular que se relaciona simultáneamente con la organización de la acción y la experiencia que tendrán los participantes (Houseman, 2012, p. 13); una práctica que estaría más definida por su forma que por su contenido -entendiendo 'forma' como una configuración relacional particular que confiere a la interacción ritual una dimensión propia-, situándose en una relación de forma/fondo respecto a la vida social ordinaria (Severi, 2014, p. 147). Esta relación otorga a la danza ritual la capacidad de engendrar símbolos y prácticas que muchas veces pueden trastocar las relaciones sociales que rigen el orden cotidiano, o al menos ponerlas en tensión.

Por otro lado, dentro de los múltiples aspectos movilizados en esta manifestación ritual encarnada por la danza ejecutada en el transcurso de la procesión, nos interesa particularmente destacar la dimensión espacial. Nuestra evidencia histórica y etnográfica muestra que la danza no solo aparece como una práctica que se "manifiesta” en la ciudad, ocupándola legítimamente por unas horas y en un día concreto. Hemos podido apreciar también que las trazas de la ciudad, con sus avenidas, calles y pasajes, actúan como coejecutores de esta práctica. Así, la danza emerge como una práctica ritual que en unos casos se apropia del espacio, en otros dialoga con ese trazado, y en muchos se ve cooptada por él. Dentro de esta amplia gama de interacciones, que muestra una coproducción práctica del continuo danza/espacio, nos interesa destacar no solo cómo la danza puede escenificar la reproducción de un orden establecido hegemónico para la agrupación religiosa y la sociedad en general, sino también su capacidad de escenificar diferencias y tensiones no resueltas dentro de los grupos sociales de referencia presentes en el recorrido de la procesión. De esta forma, el espacio se vuelve un escenario de reproducción, además de una palestra donde efectivamente se negocian, escenifican y recrean nuevas conquistas socioculturales y espaciales. 
Nuestra hipótesis de trabajo es que la procesión del Señor de los Milagros en Barcelona, y la reconfiguración espacial que conlleva, son fenómenos indisociables y se refuerzan mutuamente. La procesión no solo ha llevado a cabo una conquista progresiva del espacio público urbano. También se ha convertido en un escenario ritual donde se escenifican espacialmente diversas microconquistas internas entre las diferentes agrupaciones que forman parte de esta manifestación, las cuales, paradójicamente, tienden a subrayar la idea de unidad. El objetivo de este artículo es analizar la relación que existe entre esta manifestación ritual y la reconfiguración de la dimensión espacial que involucra.

Utilizamos principalmente una metodología de carácter etnográfico, pues es especialmente adecuada para abordar las escenificaciones e interacciones que se despliegan a lo largo de la procesión en el espacio público, al permitir un contacto directo con los actores involucrados y sus interacciones (Flick, 2002; Willis \& Trondman, 2002), y la generación de una descripción y análisis densos de los eventos (Kalocsai, 2000). El trabajo de campo se realizó durante los ańos 2016, 2017 y 2018, centrándose en el estudio de la procesión que realiza la Hermandad del Señor de los Milagros de Barcelona (нsмв), en honor al Cristo Moreno. Esta hermandad fue fundada en julio de 1992 por dos devotas peruanas, con el objetivo doble de reproducir el culto original al Señor de los Milagros practicado en Perú y congregar a los peruanos migrantes residentes en Barcelona. Actualmente, la Hermandad acoge tanto a hombres como mujeres peruanas y sus descendientes; existen roles diferenciados dentro de la organización (cófrades, sahumadoras, etc.), y hay una directiva que coordina la celebración de la festividad cada ańo. La procesión se realiza en el mes de octubre en el barrio de Les Corts (Barcelona), en los alrededores de la iglesia de Sant Ramon Nonat, que acoge a la Hermandad y, desde 1997, aloja también la imagen del Cristo Moreno durante el resto del año. La principal técnica de recolección de información utilizada fue la observación del evento. De manera complementaria se recopiló material documental asociado a la celebración en general, a la procesión en particular y a la Hermandad (incluyendo sitios web, documentos internos de la Junta directiva, entre otros). Además, se realizó una serie de entrevistas en profundidad a informantes clave de la Hermandad. Toda la información recolectada fue triangulada y analizada con la técnica de análisis de contenido (Hsieh \& Shannon, 2005).

El artículo tiene la siguiente estructura. Primero realizamos una contextualización histórica de los orígenes del culto al Señor de los Milagros y su posterior desarrollo histórico en el Perú, destacando la importancia de la dimensión espacial en la configuración de su mito de origen y en la creciente legitimación social que adquirió. En el segundo apartado describimos los orígenes de este culto en Barcelona (España) y su posterior inserción en el contexto eclesial y social, mostrando los desplazamientos urbanos que vivió la procesión desde su primer recorrido hasta la actualidad, utilizando la danza como manifestación ritual capaz de jerarquizar y reconfigurar el espacio por el que transcurre la procesión. En la tercera sección mostramos que la procesión no solo es una forma concreta de ocupación ritual del espacio público urbano, sino también un escenario particular donde se escenifican 
y recrean una serie de microconquistas espaciales entre los diferentes grupos que rinden culto al Cristo Moreno.

\section{Entre África y los Andes: orígenes del culto al Cristo de Pachacámac en Perú}

Para conocer los orígenes del culto al Señor de los Milagros, debemos sumergirnos en una historia de larga data. La historiadora María Rostworowski, siguiendo a Ávila, señala que en la época prehispánica del actual Perú se creía que el dios Pachacámac podía controlar los temblores y terremotos que caracterizan a la región, y en esa condición poseía diversos adoratorios (huacas) vinculados a su culto en la zona andina (Eeckhout, 2004; Gisbert, 2010). Después de la invasión española, el Señorío de Pachacámac quedó bajo el control de las encomiendas ibéricas. Ya en 1544, Hernán González y Bernaldo Ruiz recibieron conjuntamente las encomiendas de Pachacámac en el valle de Lurín, situado a unos 40 kilómetros al sur de Lima. Era tal el número de trabajadores en ese lugar, que pasó rápidamente a llamarse Pachacamilla, como se le conoce hasta hoy (del topónimo 'Pachacámac' y el diminutivo 'illa'). Esta fuerte presencia de población indígena hizo suponer a la historiadora que en la zona se mantuvo el culto a Pachacámac durante los inicios de la Colonia, siendo natural que las poblaciones provenientes de Pachacámac reprodujeran la imagen de la huaca que los protegía contra los sismos en su tierra natal (Rostworowski, 1992, p. 4).

Fue en ese contexto que los esclavos africanos llegados a la zona, provenientes de diversos lugares de África, España y Portugal, adoptaron el culto a Pachacámac. Habrían encontrado allí una religión estructurada con raíces fuertes y profundas, que adoptaron tanto por conveniencia personal como por temor a los fuertes sismos propios de la región. La autora agrega que esta adopción estuvo facilitada por la débil evangelización que llevaron a cabo los encomenderos de Pachacámac entre los esclavos, hecho por el cual fueron multados (1573); además del colapso demográfico que sufrió la población nativa de la época por las enfermedades y la guerra civil (Rostworowski, 1992, pp. 4-5). Pero no fue hasta 1650 que un grupo de afrodescendientes angoleños se agremió en una cofradía y levantó un local de encuentro en las afueras de Lima, en el barrio de Pachacamilla. La historia, teñida de leyenda, cuenta que un esclavo angoleño de apellido Dalcón pintó de manera rústica la imagen de un Cristo crucificado sobre una de las paredes de este recinto. En 1655 un gran terremoto sacudió Lima, derrumbando una parte importante de la ciudad. Todos los muros de adobe del local de la cofradía se desplomaron, salvo aquel donde estaba plasmada la imagen del Cristo, la cual, según señala la historia, quedó intacta. Según Vargas Ugarte (1966), esto ocasionó la primera reactivación del culto.

Pasaron los años y, en 1670, el residente Antonio León comenzó a adorar la imagen, luego de que le atribuyera la curación de una enfermedad grave (tumor). El culto se reactivó aún más, especialmente entre la gente de color, quienes "el viernes por la noche (...) se juntaban en bulliciosas celebraciones" (Rostworowski, 1992, p. 6). Las peregrinaciones a este lugar fueron intensificándose y se incorporaron prácticas como plegarias y lamentaciones, acompañadas de instrumentos musicales 
como cajas, vihuelas y arpas. A ello se sumó la práctica de rituales y danzas no cristianas asociadas a las deidades africanas tradicionales Zanajarí o Nyamatsané, a través de las cuales veneraban al Cristo de Pachacamilla (Banchero Castellano, 1976, p. 20; en Costilla, 2011, p. 8). Y aunque Pachacamilla era un barrio considerado marginal, estaba situado a menos de un kilómetro de la plaza mayor y de los palacios virreinal y arzobispal de Lima (Figura 1).

\section{Figura I | Plano de la Ciudad de los Reyes, 1713}

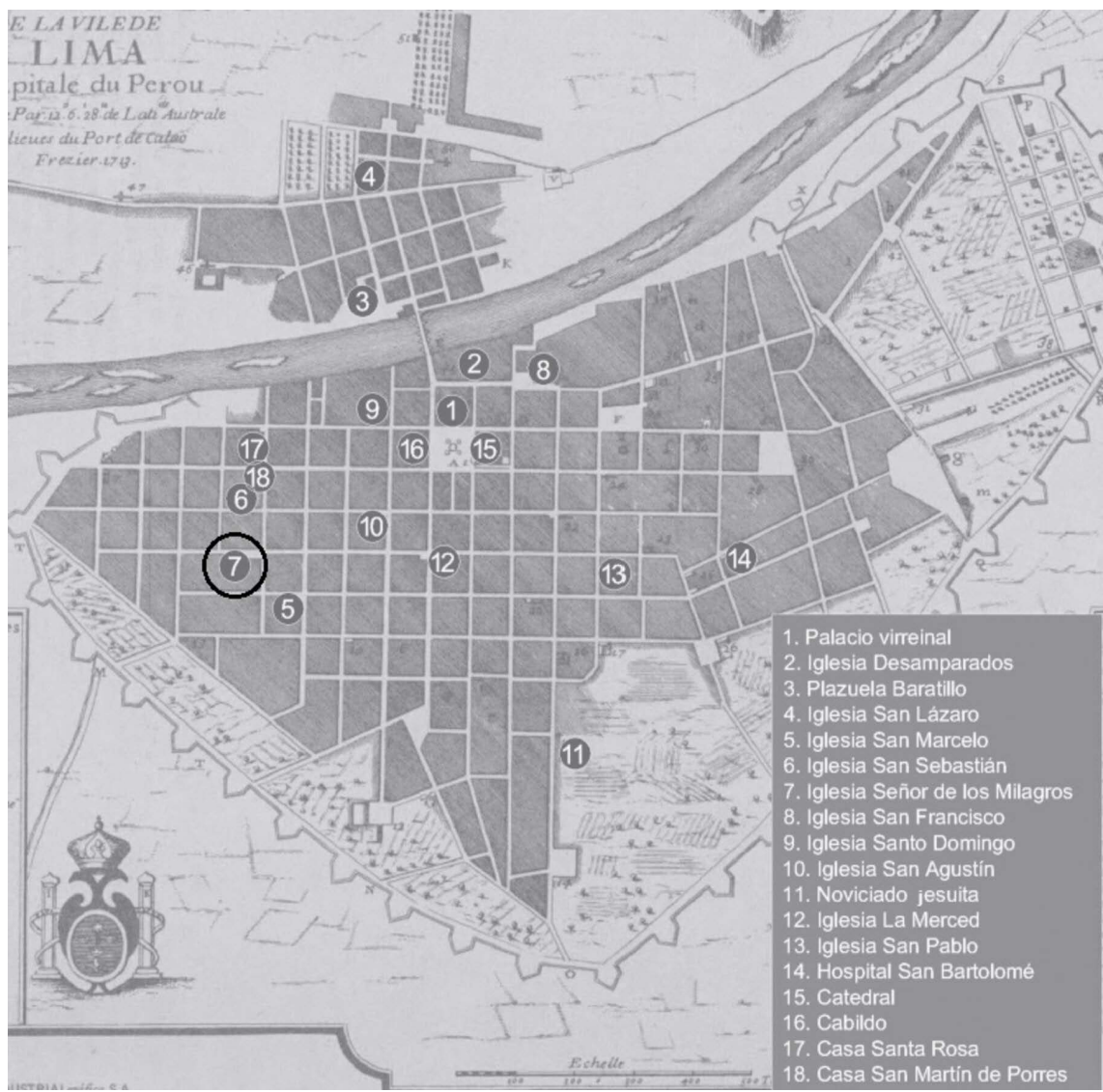

FUENTE: COSTILLA (2OI 5, P. I 7), SOBRE PLANO DE FRÉZIER

Las autoridades vieron en estas manifestaciones un culto poco decoroso y una especie de "desorden de las gentes de ambos sexos que ya pasaba, con pretexto de devoción a escándalo" (Colmenares, 1771, p. 7; en Costilla, 2015, p. 158). Además, el Cabildo de la ciudad veía con desconfianza las cofradías de negros, sobre todo después de las quejas recibidas del vecindario debido a las "ruidosas celebraciones". A esto se le sumaba la presunción de que allí se fraguaban asaltos y delitos, junto a la posible continuidad de prácticas consideradas paganas y supersticiones (Costilla, 2011, p. 10; Rostworowski, 1992; Vargas Ugarte, 1966). 
El párroco de la iglesia de San Sebastián solicitó al virrey que interviniera este culto popular, prohibiendo las reuniones y borrando la imagen del Cristo Moreno. La leyenda relata que una vez que un pintor indígena intentó subir por unas escaleras para borrar la imagen sacra, comenzó a sentir temblores y escalofríos, no pudiendo concretar la tarea asignada. Un segundo hombre intentó hacer lo mismo, pero aseguró haber visto algo en la imagen que le impidió raspar su superficie. Por último, un soldado insistió, pero desistió, testimoniando que mientras miraba la imagen, esta se tornaba más y más bella y su corona de espinas reverdecía. Finalmente, el virrey y el vicario revocaron su orden y autorizaron su culto, alzándose posteriormente una ermita en este lugar y celebrándose la primera misa oficial el 14 de septiembre de 1671 (Banchero, 1976). En apoyo de la leyenda, hay una cédula real del 19 de abril de 1681 donde se menciona que el intento de borrar la imagen del Cristo se llevó a cabo bajo el régimen de Cueste Castellar. La cédula es también la primera fuente en la que la imagen del Cristo de Pachacamilla es llamada oficialmente "El Cristo de los Milagros" (Rostworowski, 1992, p. 154).

El 20 de octubre de 1687, un violento terremoto asoló nuevamente la ciudad de Lima, derribando la ermita del Señor de los Milagros, pero la pared donde estaba su imagen continuó en pie. En aquel entonces, Sebastián Atunaño, feligrés de origen español que fue uno de los principales benefactores del culto, tenía una copia en óleo de la imagen (con el fin de resguardarla), y decidió sacarla en procesión por las calles de Pachacamilla luego del evento. Posteriormente, como una medida de protección contra la serie de temblores y terremotos que constantemente sacudían Lima, el Cabildo de esta ciudad declaró el 21 de septiembre de 1715 al Cristo de los Milagros, "Patrono Jurado por la Ciudad de los Reyes contra los temblores que azotan la tierra". Desde entonces quedó oficializado su culto y comenzó a ser llamado como "Señor de los Milagros" (Banchero, 1995).

Rostworowski sostiene que el terremoto con el cual más se identifica al Cristo Morado -que también así se le suele llamar, por el color de las vestimentas con que se le asocia- es el que ocurrió el 28 de octubre de 1746, uno de los más fuertes y destructivos de la historia de Lima. Después de este evento, la fecha de la procesión anual se cambió del 14 de septiembre al 28 de octubre. Desde entonces, el culto al Cristo de Pachacamilla siguió su ascenso (Rostworowski, 1992, p. 8). Costilla (2016) agrega que ya en la segunda mitad del siglo xvin (1771), el Señor de los Milagros se constituyó en un símbolo de devoción que integraba a toda la sociedad colonial, con sus distintas etnias y estamentos, bajo un significado primordial: proteger la ciudad (p. 169).

Desde fines del siglo xix y hasta el siglo xxi, se observa una multiplicación y diversificación del culto, proceso que ha sido acompañado por su revitalización, junto a un mayor reconocimiento por parte de la sociedad y su creciente oficialización en el ámbito eclesial y civil (Costilla, 2011, p. 15). Si bien durante la década de 1920 el culto seguía muy ligado a la población afrodescendiente, en 1928 se comenzó a aceptar miembros de otros orígenes étnicos. No obstante, no fue sino hasta los años cincuenta que se produjo una transformación importantísima para la sociedad peruana y también para esta manifestación religiosa, pues en esa época comenzaron a producirse grandes migraciones internas campo-ciudad, y 
Lima se vio crecientemente ocupada por poblaciones indígenas, mestizas e incluso extranjeras (Maguińa, 2016). Todos estos grupos fueron incorporándose al culto, junto a la creciente figuración de las elites limeñas. En esta misma época, la imagen del Cristo comenzó a ser pieza clave del imaginario nacionalista y se convirtió en bastión identitario del mismo, el cual fue movilizado por un Estado que exaltó su carácter mestizo y subrayó que se trataba de un símbolo que representaba a una nación y ciudad fundadas en la diversidad cultural. No obstante, muchos no veían con buenos ojos esta diversidad expresada ritualmente en la urbe, señalando que se trataba de una práctica "plebe" y "tan etíope en sus formas rituales", donde se expresaba aún "el simplismo y afán exhibicionista de los mulatos" (Herald, 1955; en Costilla, 2016, p. 161).

Finalmente, con motivo del 350 aniversario del Seńor de los Milagros, el papa Juan Pablo II envió una carta donde manifestaba su reconocimiento como santo patrón de Lima (Costilla, 2011, p. 7), evidenciando una clara institucionalización y oficialización del culto. De manera paralela, se produjo un fenómeno mundial que hizo posible su internacionalización: la migración desde la segunda mitad del siglo xx hasta hoy. Desde entonces, el Cristo Moreno sigue sumando adherentes e invadiendo espacios urbanos con sus procesiones en todo el globo. Añadamos que el 15 de octubre de 2005, la Santa Sede, en coordinación con el Arzobispado de Lima, designó por unanimidad nombrar al Señor de los Milagros, Patrono de los Peruanos Residentes e Inmigrantes.

\section{Afianzamiento en el espacio y juegos identitarios: las danzas}

La devoción hacia la imagen del Señor de los Milagros se extiende actualmente por todo el mundo (Altamirano, 2000; Paerregaard, 2008), debido a la migración reciente de la población de origen peruano (Merino, 2002; Berg \& Tamagno, 2004). Como en tantas otras ciudades, Barcelona (España) vio nacer a la Hermandad que lleva su nombre en julio de 1992, cuando las peruanas y fieles devotas Rosa Uchuya y Rosa Cruzatt solicitaron una misa al Arzobispado de la ciudad para que se celebrara al Cristo Moreno en la catedral de Santa Cruz y Santa Eulalia de Barcelona, al tiempo que comenzaron a realizar las gestiones para traer desde Perú un óleo con la imagen del Señor de los Milagros. Sin embargo, en aquel entonces el colectivo peruano era minoritario en la ciudad y "la invitación para que participaran de este culto se realizó en lugares públicos comunes que visitaban los peruanos, como restaurantes y plazas" (GD_HSMB_2018), como relató Rosa Uchuya, una de las fundadoras de la Hermandad de Barcelona.

Este lento proceso de apropiación del espacio público, que aparentemente nace de una iniciativa personal, es un primer intento de (re)organizar prácticas y creencias religiosas originarias del país de procedencia a través de un proceso de reterritorialización de santos y vírgenes locales (Hervieu-Léger, 1993, 1999; Levitt \& Schiller, 2004). Recordemos que desde el momento mismo en que hombres y mujeres migran a otros lugares se construyen espacios, tanto culturales como religiosos, a través de las comunidades locales que buscan insertarse en un nuevo territorio (Hannerz, 1996). Son precisamente las tradiciones un vehículo que permite 
un complejo proceso por el cual los inmigrantes construyen campos sociales que unen su país de origen con el país en el que se establecen.

El 18 de octubre de 1992 se realizó la primera procesión en torno al Señor de los Milagros alrededor de uno de los lugares más emblemáticos para el catolicismo en la ciudad de Barcelona, la catedral. Desde entonces, los cambios en la procesión han sido notorios y destacables. En primer lugar, ha aumentado considerablemente el número de devotos y devotas hacia el culto, llegando a superar las mil personas durante los momentos de mayor efervescencia del recorrido procesional que se despliega en la urbe. En segundo lugar, y a diferencia de cómo se gestó en sus inicios, la procesión cuenta actualmente con todos los permisos que exige la alcaldía de la ciudad para que pueda transitar durante casi siete horas, cada tercer domingo del mes de octubre, por las calles que circundan la parroquia de Sant Ramon Nonat, lugar donde se aloja la imagen durante el resto del año. Esta ocupación del espacio público incluye cortes del tráfico rodado en la avenida frente a la parroquia, anulación de paradas de autobuses, alteraciones del transporte público, entre otros. No menos importante es insistir, en tercer lugar, en que la procesión discurre por un lugar diferente al de sus inicios: si bien comenzó en el centro de la ciudad de Barcelona y "durante cinco años sin permisos, ni nada” (GD_HSMB_2018), desde 1997 recorre el barrio de Les Corts, el cual está situado en la periferia de la ciudad y alejado del lugar privilegiado y central del primer lustro.

Analizando el recorrido como una apropiación espacial extracotidiana, pretendemos explorar el vínculo entre una de las manifestaciones más claras del movimiento dentro de la misma procesión, la danza, y el fragmento de ciudad que se ocupa legítimamente durante el recorrido de la procesión. A través del análisis de dos danzas concretas, como la marinera y la danza de las tijeras, evidenciaremos, por una parte, que las trazas de la ciudad, con sus avenidas, calles y pasajes, actúan como coproductoras del movimiento; y por otra, que concebimos la danza como una forma ritual específica a través de la cual se habitan y reconstruyen estos espacios durante la celebración.

\section{La marinera: unidad de peruanos y católicos}

Uno de los elementos que evidencia la doble identificación entre lo religioso y lo nacional durante la celebración es, sin duda alguna, la danza de la marinera. A lo largo del trayecto de la procesión de Barcelona, las diversas agrupaciones participantes ejecutan múltiples danzas en honor al Seńor de los Milagros. No obstante, esta danza es absolutamente dominante. Como se aprecia en la Tabla 1 y en la Figura 2, la marinera da inicio y cierre al recorrido de la procesión y es la danza más presente durante la celebración. Además, suele ser la manifestación más vitoreada por parte de los participantes, la que congrega a mayor número de fieles y que suele concluirse con un enérgico y distintivo grito de “¿Qué viva el Perú!”, entre otros. 
TABLA I | Estaciones, agrupaciones y danzas en la procesión del Señor de los Milagros. Barcelona, 2016

\begin{tabular}{|l|l|l|}
\hline ESTACióN & \multicolumn{1}{|c|}{ AGRUPACIONES } & MÚSICA Y DANZA \\
\hline 0 & $\begin{array}{l}\text { Academia de Marinera de Perú en Barcelona y Centro Peruano en } \\
\text { Barcelona }\end{array}$ & Marinera y huayno \\
\hline $1^{\circ}$ & Consulado General del Perú en Barcelona & Marinera \\
\hline $2^{\circ}$ & Centro Peruano en Barcelona & Huayno \\
\hline $3^{\circ}$ & $\begin{array}{l}\text { Asociación Cultural de Proyección y Extensión Social (ACPES) y } \\
\text { Chalanes de Barcelona }\end{array}$ & Vals y marinera \\
\hline $4^{\circ}$ & San Pedrito de Chimbote, Barcelona & Marinera \\
\hline $5^{\circ}$ & Agrupación Danza de las Tijeras & Danza de las tijeras \\
\hline $6^{\circ}$ & Club de Vóley Señor de los Milagros. Barcelona - España & \\
\hline $7^{\circ}$ & Academia de Marinera, Perú & Marinera \\
\hline $8^{\circ}$ & Asociación Gitanos Virgen de la Puerta & Danza gitana \\
\hline $9^{\circ}$ & Hermandad Señor de los Milagros: Barcelona, Grone - Comando Svr & Marinera \\
\hline 0 & Señor de los Milagros y cargadores (Hermandad) & Marinera \\
\hline
\end{tabular}

FUENTE: ELABORACIÓN PROPIA

Figura 2 | Mapa del recorrido de la Procesión del Señor de los Milagros en Sant Ramon Nonat. Barcelona, 2016

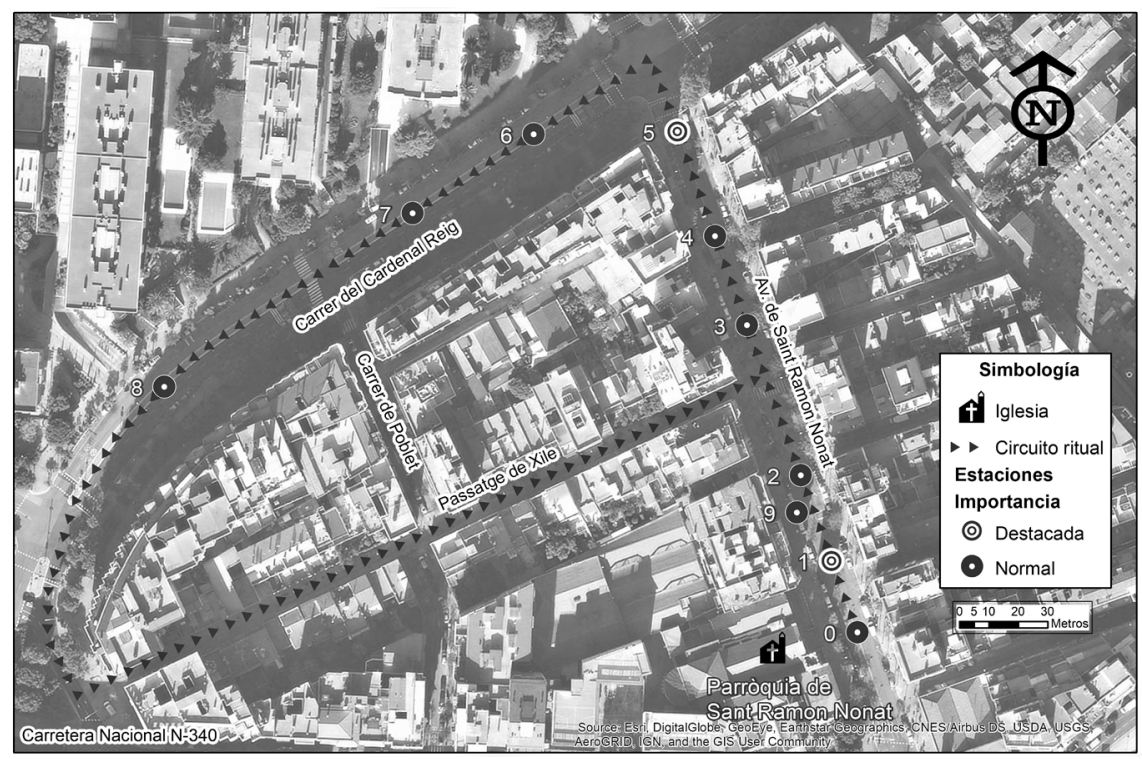

FUENTE: ELABORACIÓN PROPIA, SOBRE IMAGEN DIGITAL ESRI, DIGITALGLOBE

La marinera es una danza de pareja suelta mixta que es especialmente conocida en la costa del Perú, si bien sus características específicas dependen de sus variantes regionales, pues existen la marinera limeńa, la norteña, puneña, arequipeńa y andina. Actualmente es considerada Patrimonio Cultural de la Nación y para muchos es 
"la reina y señora de todos los bailes". Resulta especialmente importante recordar sus orígenes históricos y el estrecho vínculo con el nacionalismo peruano, que se remonta hacia el final de la guerra entre la Confederación Perú-Boliviana y Chile (1836-1839), cuando las tropas vencedoras del Ejército Unido Restaurador de Chile trajeron al Perú una danza denominada "zamacueca chilena". Esta danza se convirtió en el baile más popular durante las décadas de 1860 y 1870, haciéndose conocida como "chilena". Sin embargo, en 1879 adoptó el nombre de "marinera" gracias a la iniciativa de Abelardo Gamarra (conocido como "El Tunante"), quien decidió rebautizarla para honrar a la Marina de Guerra del Perú que luchó contra Chile. Con ello buscaba ensalzar la idea de nación peruana y eliminar cualquier vestigio que se refiriera al país contendor (Tompkins, 1981), como se aprecia en este documento publicado en prensa y firmado por el propio Gamarra:

\begin{abstract}
No más chilenas. - Los músicos y poetas criollos tratan de poner punto final a los bailes conocidos con el nombre de chilenas; quieren que lo nacional, lo formado en el país no lleve nombre extranjero: se han propuesto bautizar, pues, los bailes que tienen el aire y la letra de lo que se lla[ma]ba chilena, con el nombre de Marineras. (Abelardo Gamarra Rondó, El Nacional, 8 de marzo de 1879)
\end{abstract}

Consecuentemente, la marinera se convirtió en una danza que desempeńa un rol clave para la población peruana en muchos actos tanto cívicos como militares y religiosos, adquiriendo sin duda alguna un carácter especial cuando se interpreta lejos del Perú. El hecho de que tenga cabida en el contexto de una procesión marcadamente religiosa, como la del Señor de los Milagros (Figura 3), no hace más que ahondar en la idea de que identidad nacional y religiosa se complementan y refuerzan mutuamente en el país de acogida (Fernández-Mostaza \& Muñoz, 2018).

FIGURA 3 | Danzantes de marinera en las afueras de la iglesia Sant Ramon Nonat. Barcelona, 2016

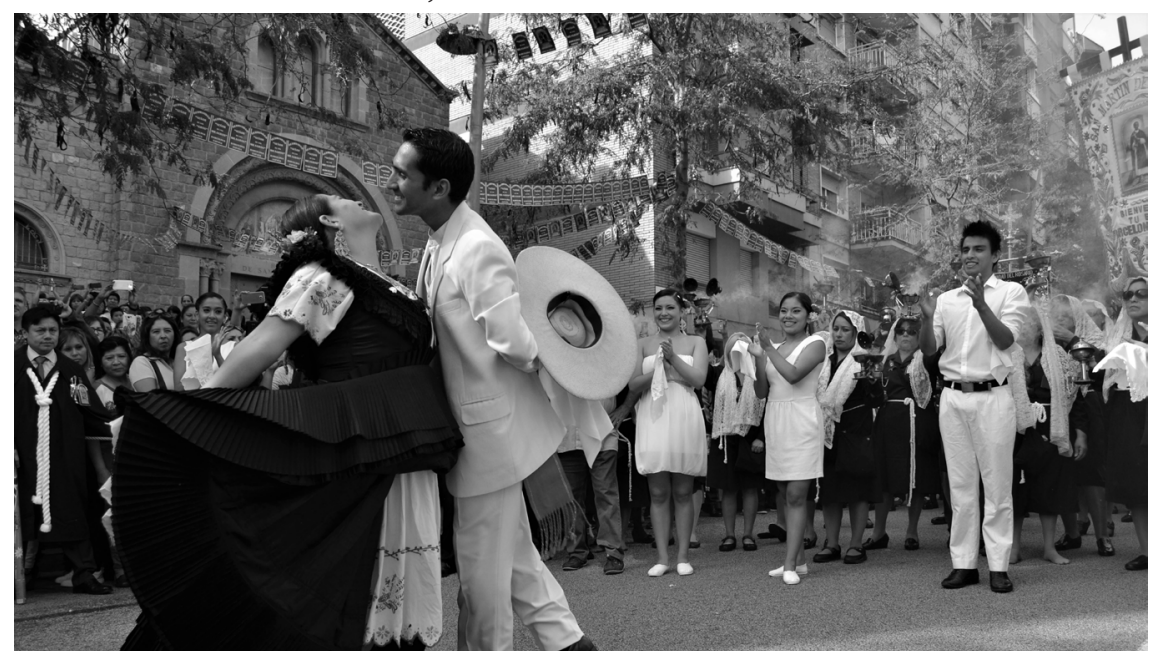

FUENTE: FOTOGRAFÍA DE WILSON MUÑOZ 
De manera más concreta, y si volvemos nuevamente nuestra mirada a la etnografía de la celebración, podemos constatar de manera general cómo la procesión y la reconfiguración espacial son fenómenos coproducidos ritualmente. En concreto, las danzas escenifican espacial y ritualmente microconquistas y discrepancias entre las distintas agrupaciones y participantes, dando muestras de diferenciación y desigualdad. Hemos podido constatar que un modo de mostrar dicha jerarquización es a través de la danza de la marinera, como se aprecia en la Tabla 1 y en la Figura 2. Esta danza: i) es preeminente en la organización espacio-temporal de las estaciones -cada uno de los puntos en el recorrido donde se realiza algún ritual-, pues da inicio y finaliza la procesión; y ii) explicita una clara jerarquización respecto al resto de estaciones donde no se hace presente, pues en estas últimas las danzas normalmente no exigen tamaña ocupación del espacio público o la prohibición del tránsito rodado. Pero, además, existe un tercer elemento que es necesario destacar, ya que, iii) se trata de una de las danzas más significativas, tanto para los celebrantes en general como para sus bailarines, pues evoca de manera conjunta la fe en el Señor de los Milagros, a la familia y, de manera más general, al Perú, especialmente para las generaciones que nacieron en este país. Se transforma así en un soporte emocional, social y cultural para los devotos en Barcelona. Este último punto es desarrollado a continuación.

Si nos acercamos a la experiencia particular que establecen los devotos del Señor de los Milagros durante su celebración, podemos apreciar que es muy variada, pues los migrantes que transmiten los elementos que logran conjugar las prácticas religiosas limeñas y las propiamente hibridizadas en este colectivo, también lo son: en primer lugar, están los adultos y adultos mayores migrantes; en segundo lugar, los practicantes y devotos del barrio, también migrantes y no necesariamente "hermanos peruanos"; y finalmente, las generaciones ya nacidas en el país de acogida.

Un ejemplo concreto del primer grupo es el caso de Marta Chavín (nombre ficticio). Ella tiene 45 ańos, estudió leyes, trabajó como militar (Fuerza Aérea) en Perú durante quince años y se vino a Barcelona para realizar un máster en sociología y criminología jurídico-penal. Una vez que decidió radicarse en la ciudad condal, y luego de traer a su hija desde Perú para que viviera definitivamente con ella, fundó en 2016 la Asociación Cultural Hanan Pacha. Esta es una organización sin fines de lucro orientada al rescate de las tradiciones y costumbres peruanas, centrada especialmente en la danza (actividad que declara practicar desde que tiene uso de razón), y que busca inculcar esta práctica cultural sobre todo en las nuevas generaciones. Actualmente reúne a unas veinte familias, la mayoría peruanas, o con algún padre o madre español o española, lo que es leído casi graciosamente por ella como una nueva "reconquista, porque los chicos que son de Espańa ya comen peruano, bailan peruano”. Como católica y devota del Señor de los Milagros, cuando la Asociación fue contactada por la Hermandad para que formara parte del recorrido procesional que realiza el Cristo Moreno en Barcelona, la alegría de Marta fue máxima. Ella misma nos cuenta qué significa personalmente el Señor de los Milagros y la celebración de su festividad en Barcelona. 
¿Qué sentimiento te genera a ti el Señor de los Milagros y la procesión?

Para mí me representa a mi familia. Para mí son mis hijos. Tengo yo una fe enorme, porque yo creo que sin la fe no hubiéramos podido avanzar mucho, al menos en mi caso. Yo, la fe es el único soporte que tengo para hacer las cosas que yo hago. Por ejemplo... uy, eso me pone... [no puede hablar. Se emociona, se le hace un nudo en la garganta y comienza a llorar]. El no ver a la familia. Yo creo que, si no hubiera fe, yo no... [Llora nuevamente. Se interrumpe la entrevista] (...) Bueno, es eso, el soporte... es básicamente eso. Para mí es el soporte. Sin eso, pues... buff, me vendría abajo. (A2_E4_190323)

Un sentimiento y experiencia que comparte (con matices) con otras y otros devotos peruanos. En este caso en particular, Marta nos entrega además un relato concreto de lo que significa danzar la marinera.

Yo no viajo hace siete años, no viajo hace mucho... y lo extraño mucho [se refiere al Perú]. Sí, han venido mi mamá, mi papá, pero yo no voy hace muchos, muchos [énfasis] años... Lo extraño un montón. Yo, lugar que veo, tiempo que veo, si hay algo peruano de comida o de lo que sea, sea bonito o sea feo, entro a mirar lo que hay [risas]. No sé, me envían cosas de allá, la comida me provoca mucho, pero claro, extrañar, extraño... A veces sueńo, sueño algo, que ya he estado allá y digo: "uy, madre mía, estoy mal. Debo ir a hacer yoga o algo" (...) Y digo: "No, no, no puede ser”. ¿Entonces qué hago? Bailo. Que el bailar me acerca... me despejo totalmente. Y verlos, verlos bailar... porque de nada sirve que una persona lo haga sola. No tiene ningún sentido... Tú lo disfrutas más cuando es así, en grupo, con gente... Te diviertes. (A2_E4_190323)

Por último, el relato de Marta da cuenta de un aspecto común que comparten los danzantes de marinera: conocer el vínculo simbólico y ritual que existe entre la marinera y la expresión de nacionalismo peruano, lo cual se expresa explícitamente en los significados e intenciones de quienes enseñan y practican esta danza. Marta nos lo relató así:

Buscamos, por ejemplo, que la presentación busque faldas blancas o todo blanco con cinturón rojo, que representa la bandera... O negro, con fajín rojo y blusa blanca, que también representa la bandera (...) [y] Nosotros el pañuelo lo utilizamos como cuando hay guerra y dicen paz, pues el pañuelo viene a representar la felicidad... porque es el momento más emotivo del baile, cuando todo está alegre... cuando cuaja una relación, que si cuaja esto es la felicidad, ¿̨no? Entonces busco eso, para que los niños lo entiendan de esa manera... porque es el momento de más fuerza.

\section{La danza de las tijeras: devoción, idolatría y espectáculo}

En nuestra investigación pudimos constatar que la semántica oficial dominante que utilizan las diversas autoridades religiosas y políticas que participan en la procesión, así como los altos cargos de las cofradías y muchos de los celebrantes, remiten a la figura de la unidad. No obstante, la procesión también es un escenario utilizado para representar y reproducir una serie de diferencias respecto a este discurso 
dominante. Así, durante los años 2016 y 2018 se han presentado danzas como el huayno, la danza de las tijeras, la danza del baile gitano de la Virgen de la Puerta, el festejo agrario, una danza tradicional ecuatoriana, e incluso la salsa, entre muchas otras. Además, agrupaciones como el Club de Vóley Señor de los Milagros y el Comando Svr Barcelona Grone del club de fútbol Alianza Lima, también tienen una representación en la celebración. No obstante, la ubicación que poseen estas manifestaciones dentro de la procesión, tanto espacial como temporal, así como el tipo de interacciones que se producen entre los hermanos que cargan la imagen del Cristo y los integrantes de estas estaciones, dan cuenta de su posición secundaria o marginal respecto a otras estaciones más centrales y que suelen remitir a la unidad nacional (como la estación del Consulado, de la Asociación de Marineras, etc.). Así, si bien son parte de la estructura misma del ritual, suelen manifestarse en las estaciones intermedias de la procesión y transcurren por calles y pasajes en los que no está prohibido totalmente el tráfico rodado, lo que significa una constante presencia y control de la guardia urbana.

Analizar la danza de las tijeras nos permite mostrar cómo se escenifica la referencia a la diferencia dentro de la celebración. Para esto mostraremos su origen, sus principales características, su posición y la interacción que establecen sus danzantes con los cargadores y la imagen del Cristo durante la procesión.

La danza de las tijeras ha sido interpretada tradicionalmente por los habitantes de los pueblos y las comunidades quechuas del sur de la cordillera de los Andes centrales del Perú. Aunque se trata de una danza típicamente andina (Tomoeda \& Millones, 1998), desde hace algunas décadas ha comenzado a ser interpretada por poblaciones de las zonas urbanas del país. Esta danza ritual, que reviste la forma de una competición, suele bailarse durante la estación seca del año y su ejecución coincide con importantes fases del calendario agrícola (Arce, 2006). En la sierra se baila desde abril hasta diciembre en todas las ferias agrícolas y religiosas importantes. Ella debe su nombre a las dos hojas de metal pulimentado, parecidas a las de las tijeras, que los bailarines portan en su mano derecha y que mueven para emitir un particular sonido metalizado (Álvarez, 2007).

La danza se ejecuta en cuadrillas formadas por un bailarín, un arpista y un violinista. Cada cuadrilla suele representar a una comunidad o un pueblo determinado (Montoya, 2007). Para ejecutar la danza se ponen frente a frente dos cuadrillas y los bailarines, al ritmo de las melodías interpretadas por los músicos que acompañan, tienen que entrechocar las hojas de metal y librar un duelo coreográfico de pasos de danza, acrobacias y movimientos diversos, el cual es seguido por una secuencia individual, donde el riesgo de los pasos de baile se incrementa progresivamente. Este duelo entre los bailarines, llamado atipanakuy en quechua, puede durar hasta diez horas, y los criterios para determinar quién es el vencedor son la capacidad física de los ejecutantes, la calidad de los instrumentos y la competencia de los músicos que acompañan la danza (Zevallos-Aguilar, 2003).

Durante la celebración del Señor de los Milagros en 2016, esta danza fue representada en la estación que organizan sus ejecutores en la intersección de la avenida Sant Ramon Nonat y la calle del Cardenal Reig (Figura 2). Se trata de una estación peculiar, por diversos motivos: i) está ubicada en una intersección, siendo la avenida 
el centro neurálgico de la celebración (donde se danza la marinera), mientras que la calle solo está parcialmente cortada al tráfico; ii) es considerada más un espectáculo que una parte esencial de la celebración, al no incluir mayores referencias simbólicas a la unidad como hermanos peruanos o devotos durante la danza (como ocurre con la entonación del himno del Perú o el himno del Señor de los Milagros); y iii) se aprecian claros signos de molestia por parte de los cargadores al no desplegarse la soga frente a ellos, desapareciendo consecuentemente la idea de construcción de un escenario (vía la soga) en el que se interactúa con la imagen del Cristo Moreno. Además, en la ocasión, solo pasada esta estación las mujeres devotas pudieron cargar la imagen del Cristo.

En segundo lugar, la conformación de la estación era también bastante particular. A diferencia de la mayoría de las estaciones, esta no tenía altar ni ninguna imagen de Cristo, del Señor de los Milagros, de la Virgen ni de ningún santo. La estación estaba conformada por una improvisada mesa armada con dos sillas y una tabla horizontal, cubierta por un aguayo o lliclla predominantemente de color negro, y dos ramilletes de rosas ubicados en los extremos de la mesa (destinados al Señor de los Milagros). Sobre el aguayo había diversos DvD musicales y audiovisuales que habían producido tanto el dueto musical que interpretaban las arpas andinas (conocidos como "Los hermanos Zevallos"), como el dueto de bailarines encabezados por su cabecilla, Rómulo Lifoncio Lliuyac. Todos los DVD se podían comprar en este lugar y también se podía contratar el servicio de los músicos y bailarines, siendo no pocas las personas que querían fotografiarse con los protagonistas del baile.

Si nos centramos en la procesión y en la ejecución de esta peculiar agrupación, apreciamos que los bailarines ocuparon absolutamente todo el espacio que tenían disponible. Su danza emulaba una competencia entre ambos bailarines, donde se medía la calidad de sus acrobacias. El primero en danzar fue un integrante adulto vestido con un traje blanco. Mientras ejecutaba el baile, el sonido del metálico golpeteo de las tijeras inundaba el lugar y la gente aplaudía alegremente las llamativas acrobacias. La segunda danza estuvo a cargo del integrante de mayor edad, quien interactuó mucho más con el público. Hacía bromas, reía, detenía graciosamente su danza para hacerse fotos, etc. Se trataba de un verdadero espectáculo y se evidenciaba su experiencia en este ámbito. Su manejo escénico era evidente. Su autor era el más conocido danzante de tijeras peruano a nivel internacional, Rómulo Lifoncio Lliuyacc. De hecho, su nombre artístico es "El Internacional" (Figura 4). Originario de Huancavelina (Perú), lleva más de cuarenta años desarrollando esta danza a nivel profesional. Protagonizó un documental sobre ella titulado Los danzantes de la montaña sagrada (2002), donde se muestra la importancia histórica de este baile, el cual es interpretado como una forma de resistencia cultural canalizada a través del cuerpo y sus movimientos. En el año 2010, en la Casa Perú Siglo Xxi, de Barcelona, se organizó el primer concurso de danza de tijeras en la ciudad para rendir homenaje al avezado bailarín. Ese mismo año, la danza fue reconocida como Patrimonio Cultural Inmaterial de la Humanidad. 
FIGURA 4 | Rómulo Lifoncio, danzante de tijeras, junto a su agrupación. Barcelona, 2016

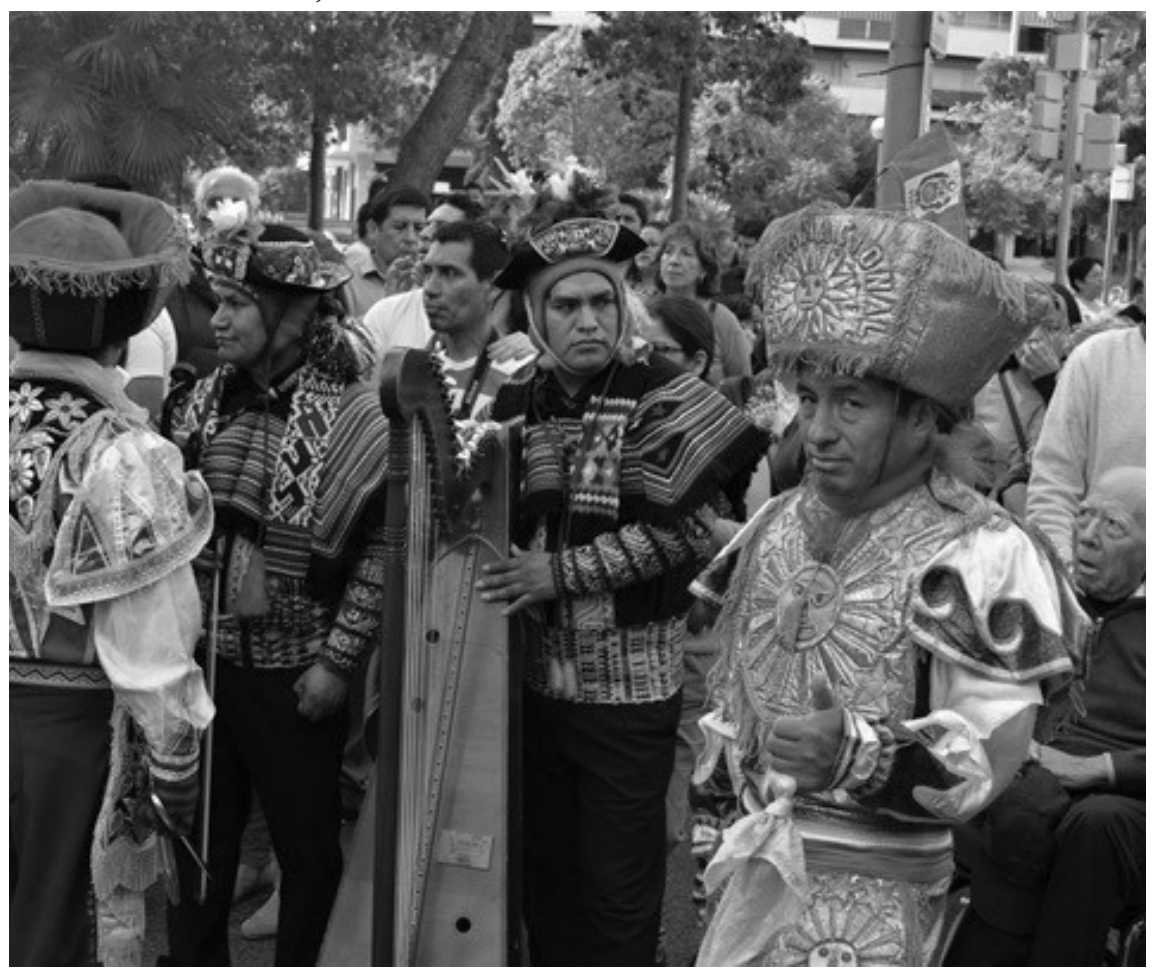

FUENTE: FOTOGRAFÍA DE WILSON MUÑOZ

Finalmente, y para nuestra sorpresa, ni en 2017 ni en 2018 la estación de la danza de las tijeras estuvo presente en la procesión. Una vez más, este espectáculo y sus protagonistas, tildados de diabólicos durante el periodo colonial en los Andes, al parecer no lograron fraguar adecuadamente con el catolicismo imperante, protagonizado esta vez por los propios peruanos, en pleno siglo xxI y en suelo europeo.

\section{Reflexiones en movimiento: hacia la construcción de un micropaisaje ritual móvil}

Al finalizar nuestro artículo, quisiéramos destacar tres ideas que resumen nuestros hallazgos y una reflexión más general que emerge de los mismos.

En primer lugar, tanto la evidencia histórica como documental muestran que el culto al Seńor de los Milagros ha vivido un doble proceso de desplazamiento y conquista espacial. Por un lado, si nos sumergimos en sus orígenes históricos, vemos que tanto el desplazamiento de indígenas que tradicionalmente veneraban a Pachacámac, desde la costa norte del Perú hacia Lima, como la incorporación de esclavos de origen africano en la misma zona durante la Colonia, dan cuenta del desplazamiento de personas consideradas marginales para la elite local. Por otro 
lado, la conformación y posterior reavivamiento de este nuevo culto, afincado originalmente en el barrio marginal de Pachacámac, muestra también la constante lucha de esta población por un reconocimiento del culto, vinculado a su manifestación en el espacio público. Tuvieron que pasar más de cuatro siglos para que, ya adentrado el siglo xx, las elites limeńas comenzaran simultáneamente a considerar y buscar instrumentalizar este culto, entendido esta vez como una manifestación nacional de la peruanidad, a lo cual se sumó posteriormente el reconocimiento (bastante tardío) de parte de la Iglesia católica. Desde entonces posee la estructura y estética que conocemos hasta hoy, y que arribó a Barcelona y al resto del mundo.

En el caso de la ciudad condal, este desplazamiento y conquista espacial parece marcar también la historia del Cristo Moreno. Luego de que su reconocimiento y la celebración de misas asociadas se realizaran en el centro de la ciudad, el culto se vio desplazado al barrio de Sant Ramon Nonat, un sector ubicado en los márgenes de Barcelona, donde la celebración vivió un refortalecimiento debido a la creciente participación principalmente de peruanos. Desplazamiento y (relativa) conquista espacial nuevamente entraban en juego. De manera general, apreciamos que, mientras en un primer momento estas personas y su culto hicieron su aparición en una escena central del espacio urbano, luego fueron desplazados social y espacialmente, para finalmente reacomodarse y lograr un mayor reconocimiento social y una (re)conquista espacial, siempre relativa, respecto al centro hegemónico religioso y social dominante.

En segundo lugar, hemos apreciado cómo una serie de símbolos y prácticas evidencian un mensaje que la procesión intenta promover: la unidad nacional y religiosa. Bryan (2016) sostiene que las celebraciones de ritos constituyen uno de los ámbitos de la vida social donde se puede constatar la presencia de símbolos y prácticas referidas a la unidad del grupo social de celebrantes o simpatizantes. En este caso, se intenta esculpir y escenificar ritualmente en el espacio la existencia de una peruanidad unida al culto católico del Señor de los Milagros. Si bien esto se puede apreciar en diversos elementos, quizá sea la danza de la marinera la que mejor da cuenta de este fenómeno, convirtiéndose realmente en el caballo de batalla de la procesión. La reconstrucción histórica de su estructura, contenido, estética e incluso de las experiencias individuales, muestra sus fuertes vínculos con el nacionalismo peruano nacido en la posguerra del Pacífico (conflicto militar con Chile). Y esto se aprecia también en términos rituales en la actualidad. Al analizar la estructura de la procesión, constatamos que la marinera está ubicada ritual y espacialmente en los momentos y lugares de mayor significación simbólica: al inicio de la procesión, en las estaciones más importantes y con mayor público (estación del consulado peruano, estación de la agrupación cultural peruana, el cierre de la procesión, etc.); y es la única danza que está presente a lo largo de toda la procesión. Además, se trata de una práctica altamente significativa para los bailarines, que evoca conjuntamente la fe en el Señor de los Milagros, a la familia y al Perú, transformándose así en un claro soporte emocional y sociocultural.

$\mathrm{Al}$ analizar el contenido de las letras de sus canciones, la coreografía y estética de la danza, así como también los testimonios orales, es ineludible apreciar la presencia de elementos y valores asociados al nacionalismo peruano (letras alusivas a la grandeza de lo peruano, una escenificación vinculada a la imagen de una pareja 
hacendada o urbana de buena posición socioeconómica con gestos estéticamente pulidos, la presencia de banderas, escarapelas y colores nacionales, etc.). Así hemos podido apreciar lo que aseguraba Costilla (2016): el culto al Cristo de Pachacamilla, una manifestación popular vinculada a lo indígena y al culto de afrodescendientes, fue crecientemente higienizada o blanqueada por las elites criollas y burguesas, resultando finalmente un culto donde predominan las manifestaciones nacionalistas católicas, aunque siempre tamizado por las experiencias individuales y situadas localmente. La marinera, danza ritual que parece colmar ese espacio público invadido durante la procesión, podría ser el ejemplo más claro de esto.

En tercer lugar, subrayamos que, junto a esta apropiación general llevada a cabo por la procesión, sus dirigentes y ciertas autoridades locales, también se manifiestan símbolos y prácticas consideradas marginales. Por un lado, son marginales porque dentro de la estructura de la procesión, ubicación espacial y temporal, se encuentran situadas al margen o, en el mejor de los casos, son secundarias respecto a las manifestaciones centrales. Y, por otro lado, suelen ser manifestaciones sociales o culturales asociadas a grupos marginales (considerados incluso paganos) en el Perú, lo que podría llegar a poner en cuestión esta idea de unidad nacional-católica o, al menos, a los cultores que se erigen como sus principales estandartes. La existencia y persistencia de muchas de estas manifestaciones evidencia que, si bien explícitamente la Hermandad sostiene que todas las agrupaciones forman parte de igual manera de la procesión, existen símbolos y prácticas que dan cuenta de esta especie de marginalidad que contradice, o al menos pone en tensión, dicha idea de unidad. Pudimos apreciar esto de manera ejemplar en la danza de las tijeras, tanto por sus orígenes históricos como por su puesta en escena y estética apreciadas en la procesión de 2016.

Por último, queremos ofrecer una reflexión. Hemos apreciado que las características propias del contexto social donde se desarrolla la procesión han creado una manifestación inédita. A diferencia de lo que ocurre en Lima o Perú en general, la Hermandad del Señor de los Milagros de Barcelona ha intentado dar cabida a una diversidad de agrupaciones políticas, culturales, sociales, musicales y deportivas dentro de la estructura de la procesión, otorgándoles una parada o stand dentro del recorrido que realiza por el barrio de Sant Ramon Nonat. En este sentido, la procesión le otorga espacio a un crisol de agrupaciones que dan cuenta de las diversas adscripciones que poseen los peruanos residentes que rinden culto al Cristo Moreno. Así, esta manifestación ritual transnacional aparece como un micropaisaje que da cabida, muestra y escenifica la diversidad social, cultural y étnica del Perú, al mismo tiempo que ofrece una experiencia y soporte personal altamente emotivos y significativos para los celebrantes. Aquí coincidimos con Abdullah (2009) cuando, en su análisis de los desfiles de senegaleses murid en Nueva York, argumenta que tales performances se basan en una pluralidad de repertorios identitarios e imaginarios capaces de crear nuevas "liturgias" urbanas (p. 4). De hecho, al igual que las manifestaciones de religiosidad de otras naciones o devociones, los peruanos que expresan su fe religiosa y su identidad peruana poniendo "en ruta" al Señor de los Milagros, se apropian de un particular territorio, reivindicando con ello un lugar y un espacio -o lugares y espacios- en la ciudad. Es a través de esta práctica ritual 
situada y movilizada espacialmente que la diferencia se construye en torno al Cristo, realizándose una coproducción entre el espacio y los grupos danzantes, lo que nos permitiría hablar hipotéticamente de la existencia de un micropaisaje ritual móvil. Así entendida, esta manifestación religiosa nos entregaría nuevas luces sobre cómo la actividad ritual, y el espacio público donde se manifiesta, pueden informarnos sobre la escenificación y recreación de la diversidad sociocultural y sus tensiones internas en el colectivo peruano residente en Barcelona.

\section{Agradecimientos}

Quisiéramos agradecer al Ministerio de Educación y Ciencia de España, por financiar esta investigación a través del proyecto I+D-Excelencia CsO20 I 5-66I 98-P: "The Place of Religion in Open Urban Spaces: A Comparative Case Study of Public Religious Acts and Celebrations in Madrid and Barcelona”. El primer autor agradece también a la Comisión Nacional de Investigación Científica y Tecnológica de Chile (Conicyt), Programa de Becas de Doctorado en el Extranjero (No 72150364), y al Ministerio de las Culturas, las Artes y el Patrimonio, Chile, Beca de Doctorado Chile Crea (No 516034). Por último, agradecemos a todos los miembros de la Hermandad del Señor de los Milagros de Barcelona por facilitarnos el trabajo de campo, y a Alan Rodríguez por su asesoría técnica y geográfica.

\section{Referencias bibliográficas}

Abdullah, Z. (2009). Sufis on parade: The performance of Black, African, and Muslim identities. Journal of the American Academy of Religion, 77(2), 199-237. https://doi. org/10.1093/jaarel/lfp016

Altamirano, T. (2000). Liderazgo y organización de peruanos en el exterior. Culturas transnacionales e imaginarios sobre el desarrollo. Lima: Pontificia Universidad Católica del Perú.

Álvarez, J. (2007). La danza de las Tijeras en El sexto, de José María Arguedas. Contribuciones desde Coatepec, (12), 61-84. https://www.redalyc.org/pdf/281/28101204.pdf

Arce, M. (2006). La danza de tijeras y el violín de Lucanas. Lima: Fondo Editorial Pontificia Universidad Católica del Perú.

Banchero, R. (1972). Lima y el mural de Pachacamilla. Lima: Editorial Jurídica.

Banchero, R. (1976). La verdadera historia del Señor de los Milagros. Lima: Inti-Sol.

Banchero, R. (1995). Historia del mural de Pachacamilla. Lima: Consejo Directivo del Monasterio de las Nazarenas Carmelitas Descalzas.

Berg, U. \& Tamagno, C. (2004). El Quinto Suyo: conceptualizando la diáspora peruana desde abajo y desde arriba. Las Vegas: Mimeo.

Bryan, D. (2016). Ritual, identity and nation. En R. Grayson \& F. McGarry (Eds.), Remembering 1916: The Easter Rising, the Somme and the Politics of Memory in Ireland (pp. 24-42). Cambridge, MA: Cambridge University Press. 
Costilla, J. (2011). El culto limeño al Señor de los Milagros (siglos xviı al xxi): Fundamentos históricos para repensar una devoción mestiza. Revista Peruana de Historia Eclesiástica, (13), 169-204.

Costilla, J. (2015). "Guarda y custodia" en la Ciudad de los Reyes: la construcción colectiva del culto al Señor de los Milagros (Lima, siglos xvir y xviıI). Fronteras de la Historia, 20(2), 152-179. https://revistas.icanh.gov.co/index.php/fh/article/view/79

Costilla, J. (2016). Una práctica negra que ha ganado a los blancos: símbolo, historia y devotos en el culto al Señor de los Milagros de Lima (siglos XIX-XXI). Anthropologica del Departamento de Ciencias Sociales, 34(36), 149-176. https://doi.org/10.18800/ anthropologica.201601.006

Eeckhout, P. (2004). Relatos míticos y prácticas rituales en Pachacamac. Bulletin de l'Institut français d'études andine, 33(1), 1-54. https://journals.openedition.org/bifea/5786

Fernández-Mostaza, M. E. \& Muñoz, W. (2018). A Cristo Moreno in Barcelona: The staging of identity-based unity and difference in the procession of the Lord of Miracles. Religions, 9(4), 121-137. https://doi.org/10.3390/rel9040121

Flick, U. (2002). Qualitative research - State of the art. Social Science Information, 41(1), 5-24. https://doi.org/10.1177/0539018402041001001

Gisbert, T. (2010). El cerro de Potosí y el dios Pachacámac. Chungara Revista de Antropología Chilena, 42(1), 169-180. http://dx.doi.org/10.4067/S0717-73562010000100028

Hervieu-Léger, D. (2005). La religión hilo de memoria. Barcelona: Herder.

Houseman, M. (2012). Le rouge est le noir. Essai sur le rituel. Toulouse: Presses Universitaires du Mirail.

Hsieh, H. \& Shannon, S. (2005). Three approaches to qualitative content analysis. Qualitative Health Research, 15(9), 1277-1288. http://dx.doi.org/10.1177/1049732305276687

Kalocsai, C. (2000). The multi-sited research imaginary: Notes on transnationalism and the ethnographic practice. Comparative Research Workshop, Yale University.

Levitt, P. (2001). The transnational villagers. Berkeley, CA: University of California Press.

Levitt, P. \& Schiller N. G. (2004). Conceptualizing simultaneity: A transnational social field perspective on society. The International Migration Review, 38(3), 1002-1039. https:// doi.org/10.1111/j.1747-7379.2004.tb00227.x

Maguiña, E. (2016). Esbozo de las migraciones internas en el siglo xx y primera década del siglo xxi y su relación con los modelos de desarrollo económico en el Perú. Anales Cientificos, 77(1), 17-28. http://dx.doi.org/10.21704/ac.v77i1.622

Merino, H. (2002). Historia de los inmigrantes peruanos en España. Dinámicas de exclusión e inclusión en una Europa globaliza. Madrid: Consejo Superior de Investigaciones Científicas (CsIC).

Montoya, R. (2007). El buen danzante de tijeras recoge agua con canasta. Investigaciones Sociales, 19, 15-54. https://doi.org/10.15381/is.v11i19.8044

Paerregaard, K. (2008). In the footsteps of the Lord of Miracles: The expatriation of religious icons in the Peruvian diaspora. Journal of Ethic and Migration Studies, 34(7), 10731089. https://doi.org/10.1080/13691830802230380

Rostworowski, M. (1992). Pachacámac y el Señor de los Milagros. Una trayectoria milenaria. Lima: Instituto de Estudios Peruanos.

Severi, C. (2014). Être Patrocle. Rituels et jeux funéraires dans l'Iliade. En C. Fausto \& C. Severi (Eds.), L'image rituelle (pp. 147-173). París: L’Herne. 
Tomoeda, H. \& Millones, L. (1998). El mundo del color y del movimiento: De los takis precolombinos a los danzantes de tijeras. En L. Millones, H. Tomoeda \& T. Fujii (Eds.), Senri Ethnological Reports No 9: Historia, religión y ritual de los pueblos ayacuchanos (pp. 129-142). Osaka, Japón: National Museum of Ethnology Repository.

Tompkins, W. D. (1981). The musical traditions of the blacks of coastal Peru. Los Angeles: University of California.

Vargas Ugarte, R. (1966). Historia del Santo Cristo de los Milagros. Lima: Imprenta Sanmarti.

Willis, P. \& Trondman, M. (2002). Manifesto for Ethnography. Cultural Studies - Critical Methodologies, 2(3), 394-402. https://doi.org/10.1177/153270860200200309

Zevallos-Aguilar, J. (2003). José María Arguedas's representation of la Danza de las Tijeras: A contribution to the formation of Andean culture. En C. Jáquez (Ed.), Musical migrations: Transationalism and cultural hybridity in Latin/o America. Vol. I (pp. 131146). Nueva York: Palgrave Macmillan. 